\title{
Characteristic and Introspection of Fire Accidents in Guizhou Province, China from 2008-2012
}

\author{
Huiting Yu ${ }^{1}$, Chan $\mathrm{Nie}^{1}$, Yanna Zhou ${ }^{1}$, Tao Wang ${ }^{1}$, Xiuquan Shi ${ }^{1,2^{*}}$ \\ ${ }^{I}$ Department of Epidemiology and Health Statistics, School of Public Health, Zunyi Medical University, Zunyi, \\ Guizhou, China \\ ${ }^{2}$ Center for Injury Research and Policy \& Center for Pediatric Trauma Research, The Research Institute at \\ Nationwide Children's Hospital, The Ohio State University College of Medicine, Columbus, OH, USA
}

*Corresponding Author: Xiuquan Shi, Department of Epidemiology and Health Statistics, School of Public Health, Zunyi Medical University, Zunyi, Guizhou 563006, China, E-mail: xqshi@zmc.edu.cn

\begin{abstract}
Background: Fire accident is one of the serious disasters that threaten public safety and endanger people's life and property. Fire is often led to burns and disability, while the treatment of burns is difficult.

Objectives: To explore the fire frequency, injured persons, the death toll in fire accidents, the direct economic loss caused by fire in Guizhou province and China during 2008-2012, so as to give some target prevention measures.

Methods: The effective data relative to the fire accidents and burns were extracted from the official websites, and then we use epidemiological approach to conduct the analysis. The information is described in terms of composition ratio, and time point diagram.

Results: There are 676287 fire accidents, 3164 person were injured, and 6098 people were lost their lives in the fire accidents. It caused a direct economic loss of 9639.98 million RMB Yuan in China during 20082012. The numbers of people injured and the number of death in the fire in Guizhou province is lower in the national ranking.

Conclusion: Though the fire frequency, the numbers of injuries and death in fire accidents has decreased, however, the direct economic loss of fire has an uptrend in both Guizhou province and in whole China. Thus, we suggest that fire prevention should be paid more attention.
\end{abstract}

Keywords: Fire accidents, Fire prevention, Guizhou Province, China, Epidemiological approach

\section{INTRODUCTION}

In our social life, fire accident is one of the serious disasters that threaten public safety and endanger people's life and property. Fires caused over 300,000 deaths annually worldwide and leave millions more with permanent injuries [1]. The fire not only damages material property, but also causes the chaos of social order and the disastrous direct economic loss and indirect economic loss. Forest fires can cause catastrophic damage on natural resources ${ }^{[2]}$. In boreal forests, fire is an important part of the ecosystem that greatly influences soil respiration, which in turn affects the carbon balance ${ }^{[3]}$. Among the hazards of fire, the life and health hazards of the people should arouse the attention of medical and health practitioners. In hot summer, some news had reported that the fire accidents led to burns. Eg: "A 23-year old female master student was suffered a severe burns more than 70\% TBSA (total burn surface area, TBSA) due to gas leak". Another case reported that "A seven years old girl used the toilet water (a type of liquid for the mosquito repellent use), happened to meet with her brother playing fire, and got burned". Burns are among the most devastating of all injuries, with outcomes ranging from physical impairment and disability to emotional and physical consequences ${ }^{[4]}$. Many developed countries have high mortality rates for fire-related deaths in children aged0-14 years with steep social gradients ${ }^{[5]}$. After the fire the treatment of injured personnel causes severe disease burden to families and even society, while lamenting 
the tragedy, what should be done to the burns in the summer.

In this study, the details of fire accidents were described in Guizhou province (It locates in south west China with poor economic condition but its mountains are rich) and China from 2008 to 2012. We compared the fire accidents in Guizhou province with the whole nation. The number of injured, the number of deaths (death toll), and the economic losses resulting from the disaster have been analyzed to reveal the changing trends in the fire accidents. We aimed to clarify the characteristics of fire accidents in China especially in Guizhou province, so as to give some target suggestions on prevention measures in similar area as Guizhou.

\section{METHODS}

\subsection{Data Source}

The data source is from the Chinese statistical website.(http://www.stats.gov.cn/)and Guizhou Provincial Bureau of Statistics official website network (http://www.gz.stats.gov.cn/). Because much fire-related information during 2013-2015 is missing in the official websites, so in this study we only conduct a statistics and analysis based on the data from 2008-2012.

\subsection{The Inclusion/Exclusion Criteria and Study Design}

Table1. Definition of fire levels

\begin{tabular}{|l|l|l|l|}
\hline \multicolumn{1}{|c|}{ Definition } & \multicolumn{1}{|c|}{ Death toll } & \multicolumn{1}{|c|}{ Injuries people } & \multicolumn{1}{c|}{$\begin{array}{c}\text { Direct property loss (million } \\
\text { RMB Yuan) }\end{array}$} \\
\hline General fire & $<3$ & $<10$ & $<10$ \\
\hline Large fire & $3-10$ & $10-50$ & $10-50$ \\
\hline Major fire & $11-30$ & $51-100$ & $51-100$ \\
\hline Special major fire & $>30$ & $>100$ & $>100$ \\
\hline
\end{tabular}

\subsection{Statistical Methods}

The effective data relative to the fire accident and burns were extracted by the official website. Epidemiological approach was used to conduct the analysis.

\section{RESULTS}

The basic situation of the fire, there are 676287 fire accidents in total in our country, 3164 person were injured in the fire accidents, 6098 people were killed. The fire accidents caused a direct economic loss of 9639.98 million in China during 2008-2012. There are 135258 fire accidents, 633 injured persons, 1220 people died of fire accidents, and fire accidents caused 19279.96 million RMB Yuan property damage
The inclusion criteria should not only include the fire frequency, death toll, injured people, direct economic loss about fire accidents both in China and Guizhou province, but also available and complete. The excluding criteria, including data from more than a decade ago as well as some main data were lost. A cross-sectional study combined with the time point tracking were used in our study.

In our study, the fire levels were defined as following: (1) General fire refers 3 people following deaths, or less than 10 serious injuries, or the fire direct property loss of less than 10 million RMB Yuan. (2) Large fires refer more than 3 people and less than 10 people died, or more than 10 and less than 50 people injured, or more than 10 million RMB and less than50 million RMB Yuan of the fire direct property loss. (3) Major fire caused the death of more than 11 people and under 30 , or more than 51 people and less than 100 people injured, or more than 50 million RMB Yuan of less than 100 million RMB Yuan of the fire direct property loss. (4) Special large fires: more than 30 people killed or seriously injured more than 100 people, or the fire direct property loss of more than 100 million RMB Yuan ${ }^{[6]}$.(see Table 1).

\subsection{Definition of Fire Levels}

each year in China during 2008-2012. (See Table 2) It can be clearly seen that the fire frequency has declined, however the direct economic loss of fire has risen. (See Fig.1) The numbers of injuries and death toll in fire accident in China have declined during 20082012. (See Fig. 2).

Though the reduction of the fire accidents, the direct economic loss of fire has an upward trend from 2008-2012. It may have something with the rapid development of the society. There are much wealth in society, when a fire breaks out, it cause greater damage than before. It was also found that the fire direct economic losses in Guizhou province ranking in the middle in China between 2008 and 2012 (see Table 3). 
Table2. Four fire accidents related characteristics during 2008-2012 in China and in Guizhou

\begin{tabular}{|l|l|l|l|l|l|}
\hline \multicolumn{7}{|c|}{ Year } & $\mathbf{2 0 0 8}$ & $\mathbf{2 0 0 9}$ & $\mathbf{2 0 1 0}$ & \multicolumn{2}{c|}{$\mathbf{2 0 1 1}$} & \multicolumn{1}{c|}{$\mathbf{2 0 1 2}$} \\
\hline China & 136835 & 129381 & 132497 & 125417 & 152157 \\
\hline Fire frequency & 743 & 651 & 624 & 571 & 575 \\
\hline Injured people & 1521 & 1236 & 1205 & 1108 & 1028 \\
\hline Death toll & 1822.03 & 1623.91 & 1959.45 & 2057.43 & 2177.16 \\
\hline $\begin{array}{l}\text { Economic loss } \\
\text { (Million RMB Yuan ) }\end{array}$ & 799 & 912 & 1661 & 1170 & 959 \\
\hline Guizhou & 35 & 29 & 41 & 10 & 15 \\
\hline Fire frequency & 77 & 80 & 73 & 55 & 31 \\
\hline Injured people & 3569.14 & 3615.6 & 4566.2 & 6625.4 & 5147.2 \\
\hline $\begin{array}{l}\text { Death toll } \\
\text { Economic loss }\end{array}$ &
\end{tabular}

Table3. The national rank and proportion of fire accidents in Guizhou Province

\begin{tabular}{|l|l|l|l|l|l|l|l|l|l|l|}
\hline \multicolumn{1}{|c|}{ Index } & \multicolumn{2}{|c|}{2008} & \multicolumn{2}{c|}{2009} & \multicolumn{2}{c|}{2010} & \multicolumn{2}{c|}{2011} & \multicolumn{2}{c|}{2012} \\
\cline { 2 - 11 } & Rank & $\begin{array}{c}\text { Proporti } \\
\text { on(\%) }\end{array}$ & Rank & $\begin{array}{c}\text { Proporti } \\
\text { on(\%) }\end{array}$ & Rank & $\begin{array}{c}\text { Proporti } \\
\text { on(\%) }\end{array}$ & Rank & $\begin{array}{c}\text { Proporti } \\
\text { on(\%) }\end{array}$ & $\begin{array}{c}\text { Rank } \\
\text { Proporti } \\
\text { on( } \%)\end{array}$ \\
\hline $\begin{array}{l}\text { Fire } \\
\text { frequency }\end{array}$ & 31 & 0.6 & 30 & 0.7 & 31 & 1.3 & 27 & 0.9 & 29 & 0.6 \\
\hline $\begin{array}{l}\text { Injured } \\
\text { people }\end{array}$ & 6 & 4.7 & 8 & 4.0 & 5 & 7.0 & 22 & 1.8 & 16 & 3.0 \\
\hline Death toll & 5 & 5.0 & 4 & 5.0 & 5 & 6.0 & 4 & 4.0 & 16 & 3.0 \\
\hline $\begin{array}{l}\text { Direct } \\
\text { economic } \\
\text { loss }\end{array}$ & 20 & 2.0 & 19 & 2.0 & 4 & 2.8 & 19 & 3.2 & 20 & 2.0 \\
\hline
\end{tabular}

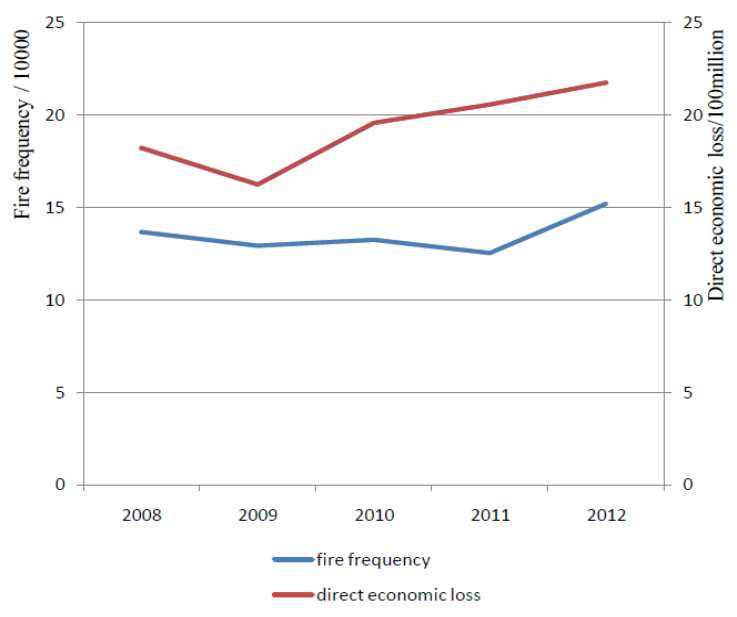

Figure1. The fire frequency and direct economic of fire in China from 2008-2012

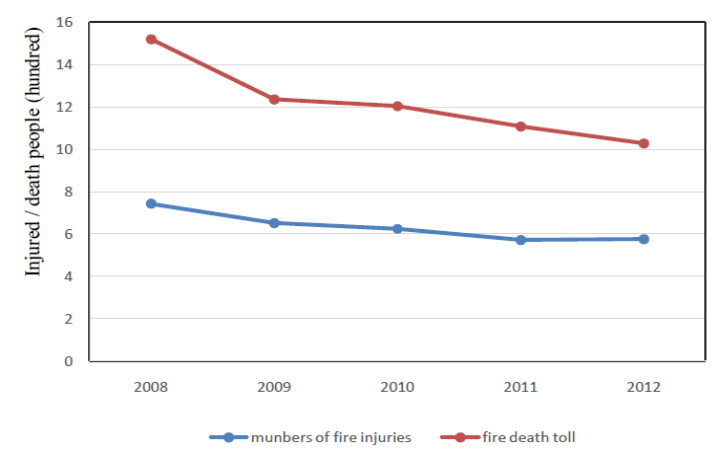

Figure2. The injured person and death toll in China during 2008-2012.
The numbers of people injured and the number of people killed in the fire in Guizhou province is lower than in the national ranking. As there are fewer general hospitals in Guizhou province (The number of hospitals in Guizhou province is 446 , and it is lower than the province average in the whole nation (480) during 2008-2012.) When a fire breaks out, the injured person cannot be saved in time. Compared with Year 2010, 128 comprehensive hospitals were increased in 2012. Accordingly, the number of fire injured persons ranked from fourth in 2011 to the sixteenth in 2012 in Guizhou province.

\section{DiSCUSSION}

Though fire frequency has declined in China, there are 633 persons in average were injured, while 1220 person died in fire accidents each year in China. Our result showed that direct economic loss of fire has increased, which means fire accidents have brought great damage in Guizhou. Not only the fires bring a heavy direct economic loss, but it also threatens people's health and lives. As fire is often accompanied by burns and disability, burn scars remain a serious physical and psychological problem for the affected people ${ }^{[7]}$. The injured person cannot work, and the treatment of burns is a great burden to families and society. It is gratifying that the number of fire accidents in 
Guizhou province has been relatively low in the national ranking.

It is possible that people in mountainous areas of Guizhou have raised awareness of forest fire prevention. Another reason may be that Guizhou's population density is small, public buildings and public mall layout less relevant, and the economic loss caused by the fire is relatively less. Even so, it suggested us that fire extinguisher equipment should be improved to reduce the loss. The safety protection system has not kept up with the development needs; and the fire safety guarantee system is not perfect for the fire prevention design and the fire extinguish force and inadequate facilities.

Although large fire accidents in recent years do not appear, however, there are several major fires. When the fire occurs, accompanied by burns, people should be leaving the scene of the fire and then treated the wound, application of cold water wash the wound, and topical ointment, avoid burn skins, and prevent infection. Infectious complications in severely burned patients present serious problems ${ }^{[8]}$, which should be treated immediately.

Dense urban population in urban areas and related hidden sources of hazards such as electrical installations and power lines may lead to the occurrence of fires as described in previous studies ${ }^{[9,10]}$. To understand the development trend of fire, complete the fire prevention work, can better guarantee the people's life and property safety. Burn wound conversion continues to remain one of the least understood and poorly treated aspects of burn care ${ }^{[11]}$. After someone burned by fire, know how to deal with the wound, so as to shorten the treatment time of burn (especial shorten the length of hospital stay), and ease the pain of the injured.

As talk about fire prevention, there are much work to do, the recently study about fire in China showed that the higher rate of education, the lower the possibility of death in a fire ${ }^{[12]}$. It is essential for us to improve people's education. First aid treatment of burn injuries reduces scarring and improves healing ${ }^{[13]}$. We should improve on the fire alert, enterprises should be the safe use of electricity, and the government should be combined with the local fire situation and characteristics. For the country level, we should pay attention to revision of the fire safety regulations, establish and improve the system of fire accident prevention regulations. Hospitals and fire services should cooperate with each ARC Journal of Public Health and Community Medicine other. However, if first aid treatment is administered immediately at the scene or prior to qualified medical treatment, burn patients have improved healing outcome ${ }^{[14]}$.

\section{ACKNOWLEDGMENTS}

This study was granted by National Natural Science Foundation of China (Grant No. 81560534, PI: Xiuquan Shi).

\section{REFERENCES}

[1] Twigg J, Christie N, Haworth J, et al. Improved Methods for Fire Risk Assessment in LowIncome and Informal Settlements [J]. International Journal of Environmental Research and Public Health. 2017; 14(2):139.

[2] Xiao Y, Zhang X, Ji P. Modeling forest fire occurrences using count-data mixed models in Qiannan autonomous prefecture of Guizhou province in China[J]. Plos One. 2015; 10(3): e0120621.

[3] $\mathrm{Hu} \mathrm{T}$, Long $\mathrm{S}, \mathrm{Hu} \mathrm{H}$, et al. Effects of fire disturbance on soil respiration in the nongrowing season in a Larix gmelinii forest in the Daxing'an Mountains, China[J]. Plos One. 2017; 12(6): e0180214.

[4] Istek Ş. The devastating effects a fire burn in a child[J]. BMJ Case Reports. 2015; doi: 10.1136/bcr-2014-206663.

[5] Deave T, Hawkins A, Kumar A, et al. Evaluating implementation of a fire-prevention injurey prevention briefing in fire-prevention injury prevention briefing in children's centres: Cluster randomised controlled trial [J]. BMC Public Health. 2017; 14(1):69.

[6] Pan Y, Zhou L, Ni T. Statistical analysis on fire situation in our country[J]. Fire technique and products information. 2012; (2):63-66.

[7] Li J,Shang H. Research on fire analysis and prevention strategy[J]. Fire science and technology. 2013;31:218.

[8] Lipovy B, Rihová H, Gregorova N, et al. Epidemiology of ventilator-associated tracheobronchitis and vantilator-associated pneumonia in patients with inhalation injury at the Burn Centre in Brno (Czech Republic).[J]. Annals of Burns \& Fire Disasters. 2011; 24(3):120-125.

[9] Jennings CR.Social and economic characteristics as determinants of residential fire risk in urban neighborhoods: A review of the literature. Fire Safety Journal. 2013; 62:13-19.

[10] Price O, Bradstock R. Countervailing effects of urbanization and vegetation extent on fire frequency on the wild land urban interface: Disentangling fuel and ignition effects. Landscape and Urban Planning. 2014;130:81-88.

[11] Salibian AA, Rosario ATD, Severo L AM, et al. Current concepts on burn wound conversion - a review of recent advances in understanding

Page $\mid 31$ 
the secondary progressions of burns[J]. Burns (Journal of the International Society for Burn Injuries). 2016;42(5):1025-1035.

[12] Li H. Statistic and Analysis of fire deaths [J]. China Public Security (Academy edition). 2017;(1):60-64.

[13] Cuttle L, Kempf M, Kravchuk O, et al. The efficacy of Aloe Vera, tea tree oil and saliva as first aid treatment for partial thickness burn injuries [J]. Burns (Journal of the International Society for Burn Injuries). 2008;34(8):11761182.

[14] Wood FM, Phillips M, Jovic T, et al. Water first aid is beneficial in humans post-burn: evidence from a bi-national cohort study. Plos One. 2016; 11:e014725.

Citation: Huiting Yu, Chan Nie, Yanna Zhou, Tao Wang, Xiuquan Shi. Characteristic and Introspection of Fire Accidents in Guizhou Province, China from 2008-2012. ARC Journal of Public Health and Community Medicine. 2017; 2(4):28-32: dx.doi.org/10.20431/2456-0596.0204005

Copyright: () 2017 Authors. This is an open-access article distributed under the terms of the Creative Commons Attribution License, which permits unrestricted use, distribution, and reproduction in any medium, provided the original author and source are credited. 